\title{
A new shear strength model incorporating influence of infill materials for rock joints
}

\author{
Murat Karakus $\cdot$ Yi Liu $\cdot$ Guangcheng Zhang • \\ Huiming Tang
}

Received: 1 May 2016/Accepted: 14 June 2016/Published online: 15 July 2016

(C) Springer International Publishing Switzerland 2016

\begin{abstract}
Overall mechanical behaviour of jointed rock masses is predominantly controlled by the shear strength of rock joints which contain infill materials. Barton's empirical model has been shown to be one of the most successful model in predicting joint shear strength (Barton and Choubey in Rock Mech 10:1-54, 1977). However, the Barton model does not express the effect of infill material explicitly, but only incorporates influence of infill into the factors of joint-wall compressive strength (JCS) and residual friction angle. Although there are a large number of studies carried out on the effects of infill materials on the shear strength of rock joints, none of them incorporated infill influence directly into the Barton's formulation. This paper investigates the effect of infill thickness on JCS and the overall joint shear strength. The interface between wall rock and infill material thicknesses ranging from 1 to $5 \mathrm{~mm}$ is simulated by using smooth-joint model. A natural joint is digitally scanned and the roughness geometry is used in all PFC3D models. The results showed that JCS does not show a significant variation at high infill thickness up to a threshold limit of $2 \mathrm{~mm}$. However, JCS decreases
\end{abstract}

M. Karakus $(\bowtie) \cdot$ Y. Liu

School of Civil, Environmental and Mining Engineering, University of Adelaide, Adelaide, SA, Australia

e-mail: murat.karakus@adelaide.edu.au

G. Zhang · H. Tang

Faculty of Engineering, China University of Geosciences, Wuhan, China drastically at low infill thickness. As expected the shear strength of filled joints reduces from fresh joints to the infill materials, as the infill thickness increases. The reduction is inversely related to the infill thickness. The reduction factor $k$ has a negative exponential relation with the normal stress, indicating that the effect of infill material is stronger at lower normal stress while effect of joint roughness is stronger at higher normal stress.

Keywords Particle flow codes · Infill · Shear strength degradation $\cdot$ Joint roughness coefficient (JRC)

\section{Introduction}

Joints and other types of discontinuities occur in abundance within a natural rock mass and the mechanical properties of the joints contribute a predominant portion of the reduction of overall rock strength. Joints and joint orientations in rock masses also influence the fracture progression in jointed rock (Wasantha et al. 2015). In regard to the stability of rock structures, one of the major controlling factors is the peak shear strength of rock joints. Due to the complexity of the mechanisms involved in joint shearing, current models are still in need of further improvement.

Barton's empirical model (Barton and Choubey 1977 ) is widely used to calculate the shear strength of 
rock joints in many researches and engineering applications. Barton's model includes the effect of infill material through the joint-wall compressive strength (JCS) and the residual friction angle. However, this effect has not been explicitly expressed. In other words, determination of JCS solely depends on Schmidt Hammer tests and residual friction angle can be obtained only after shear tests have been conducted. Relations between the two factors and mechanical properties of the infill material have not been developed. Although some experimental works on the effect of infill material have been carried out (e.g. Papaliangas et al. 1993; Indraratna and Haque 1997; Sinha and Singh 2000), no attempt is made to incorporate the results into the Barton's formulation. In addition, little has been done in numerical simulation by PFC3D to investigate a rock joint with infill material. Some models exist for rock mass and fresh joints only (Wang et al. 2016), but none of them can be directly applied to a filled joint. Therefore, the objective of this paper is to incorporate the influence of infill material into Barton's formulation and develop a useful method in modelling the filled joint by PFC3D. While flat joint model is used for the wall rock, the parallel-bond model is used for infill material. The shear strength of fresh joints is modelled using Barton's model, while the infill material follows Mohr-Coulomb's linear model.

This article is structured in the following sections: In Sect. 2, Barton's empirical model is reviewed with a discussion on a variety of methods to estimate the JRC values. The method proposed by Zhang et al. (2014) is discussed in detail. The methodology including a brief introduction to PFC3D, some builtin models, shear test set-up and validation is described in Sect. 3. Section 4 provides a discussion on the numerical analysis results. Finally, conclusions are presented in Sect. 5.

\section{Literature review}

\subsection{Barton's shear strength model}

Based on the results of two hundred direct shear tests on fresh artificial tension fractures, Barton and Choubey (1977) proposed the peak shear strength as Eq. 1. $\tau=\sigma_{n} \tan \left(J R C \log _{10} \frac{J C S}{\sigma_{n}}+\phi_{r}\right)$

where $\tau$ is the peak shear strength, $\sigma_{n}$ is the normal stress, $\phi_{r}$ is the residual friction angle, JCS is the jointwall compressive strength and JRC is the joint roughness coefficient. The model does not involve the use of cohesion, which is usually adopted in MohrCoulomb formulation.

JRC is a parameter used to quantify the roughness of the joint surface. It ranges from 0 to 20 , and higher values indicate rougher surfaces. Two methods are proposed by Barton and Choubey (1977) to estimate the JRC value. The first method is to compare the joint surface with standard profile. Another method is by back-calculation based on results of direct shear tests or tilt tests.

If the joint is fresh, JCS value is equal to the uniaxial compressive strength of the wall rock. The fundamental method to obtain the JCS value is to use the Schmidt Hammer test. A correlation between the compressive strength of rock and the Schmidt Hammer rebound number was developed by Miller (1965) in a range of 20-60, and recommended by Barton and Choubey (1977) as the standard to estimate JCS.

The residual friction angle $\phi_{r}$ can be obtained by analysing the residual shear strengths under different normal loading in direct shear tests. Barton and Choubey (1977) also proposed an expression to obtain the residual friction angle by using the basic friction angle. The residual friction angle can be conveniently obtained by tilt tests.

\subsection{Estimating JRC}

Estimation of JRC by the two methods mentioned earlier are criticized by some researchers to be subjective and incapable to be obtained by directly measured joint parameters [e.g. Maerz et al. (1990); Graselli and Egger (2003)]. Therefore, many researchers have attempted to resolve the problem. Tse and Cruden (1979) investigated a number of statistical indices and concluded significant correlations of JRC to root mean square of the first derivative of the profile $Z_{2}$ and the structure function (SF). Reeves (1985) used the average asperity gradient $Z_{1} / x D$ to predict the friction angle, by assuming a Gaussian distribution of asperity height and its first and second derivatives. Maerz et al. (1990) correlated JRC with the roughness profile index $R_{p}$. 
Other statistical indices, such root mean square of asperity height $Z_{1}$, further derivatives of asperity height and wavelength parameters, were also discussed. The centre line average roughness (cla or $Z_{0}$ ) and the root mean square $\left(Z_{1}\right)$ roughness are closely related and $Z_{1}$ is numerically greater than the $Z_{0}$ by a factor of square root of $\pi / 2$ or 1.25 (Reeves 195) Another major stream is to apply fractal theory developed by Mandelbrot (1967), to quantify the roughness the joint surface profile. Huang et al. (1992) validated the method by calculating the fractal dimension D of self-affine joints. Calculations of fractal dimension $\mathrm{D}$ by variogram and periodogram are conducted and compared in their work. Xie et al. (1999) applied the theory to quantify the heterogeneity of joint properties, and obtained a multifractal model of joint surfaces.

The method used in this research is proposed by Zhang et al. (2014). By examining 64 shear tests results, the researchers obtained a relationship between JRC and a new roughness parameter $\lambda$, which utilizes the Modified Root Mean Square 2032Z $Z_{2}^{\prime}$ of the asperity amplitude in Eq. 2 but ignores any of negative dilation angles.

$Z_{2}^{\prime}=\left[\frac{1}{M} \sum_{i=1}^{M}\left(\frac{\max \left(0, \mathrm{y}_{\mathrm{i}+1}-\mathrm{y}_{\mathrm{i}}\right)}{D x}\right)^{2}\right]^{1 / 2}$

where, $\boldsymbol{x}$ is the $\mathrm{X}$ coordinate and $\boldsymbol{y}$ is the Y coordinate and $M$ is number of profiles by dividing into equal segments. Then the roughness coefficient $\lambda$ is determined by Eq. 3 .

$\lambda=\left(\frac{h}{L}\right)^{\frac{1}{3}}\left(Z_{2}^{\prime}\right)^{\frac{2}{3}}$

where $h$ is the mean height of asperity and $L$ is the length of the profile. The coefficient automatically incorporates scale effect as the profile length has been considered. The suggested value, lower and upper limit of JRC can be obtained by Eqs. 4-6.

$$
\begin{aligned}
& J R C_{\text {suggested }}=\frac{40}{1+e^{-20 \lambda}}-20 \\
& J R C_{\text {upper }}=\frac{40}{1+e^{-30 \lambda}}-20 \\
& J R C_{\text {lower }}=\frac{40}{1+e^{-15 \lambda}}-20
\end{aligned}
$$

In this research, the theoretical range of the JRC is compared with the value given by simulation for the validation purpose.

\subsection{Effect of infill material}

Several researches have conducted laboratory tests on the influence of a specific type of infill material on joint shear behaviour. Papaliangas et al. (1993) conducted direct shear tests on replicas of natural joints filled with dry pulverised fuel ash and modelled the friction coefficient $\mu$ by Eq. 7 .

$\mu=\mu_{\text {min }}+\left(\mu_{\text {max }}-\mu_{\text {min }}\right)^{n}$

where $\mu_{\max }$ is the friction coefficient of fresh joints, $\mu_{\text {min }}$ is the minimum for the natural joint system filled with dry pulverised fuel ash and $n$ is a factor related to the ratio between infill thickness and asperity amplitude. Determination of these three factors requires experiments. Pereira (1997) investigated the rolling friction and shear behaviour of rock joints filled with sands. A model was proposed relating the rolling frictional force $T$ with the grain radius $R$, as described by Eq. 8 .

$T \leq \frac{\mu_{r o l} \times N}{R}$

where $\mu_{\text {rol }}$ is the rolling friction angle and $N$ is the normal force. However, how to determine the rolling friction angle and grain radius was not discussed. Sinha and Singh (2000) tested saw-teeth joints filled with gouge by using triaxial tests. Particle size distributions and chemical analysis were conducted for the infill gouge. Shear strength was related to infill thickness and dip angle of the joint surface, but no mathematical formulation has been proposed. Indraratna et al. (2014) considered the effect of saturation of infill material on the shear strength of filled joint. Shear tests were conducted on saw-teeth joints filled with compacted materials by using triaxial tests. A model was proposed, which includes a ratio $k_{s}$ to define limit of interference between joint surfaces. The model was validated by conducting shear tests on filled natural joints. However, determination of $k_{s}$ has not been fully described. All the current models have some shortcomings, as outlined above, and thereby the effect of infill material is considered in this research. 


\section{Methodology}

A natural joint is collected from a rockslide in Jiweishan Mountain and experimentally studied to obtain its JRC value. The 3-dimensional Particle Flow Code (PFC3D) is used to simulate shear box tests on this joint surface. The flat-joint model is adopted for the wall rock, while the smooth-joint model is used for the interface. Contact normal loading is applied by using the servo-controlled mechanism. The set-up is validated by comparing the theoretical JRC and experimental JRC obtained in simulation. Infill material is simulated by parallel-bond model. Shear box tests on filled joints are conducted by using PFC3D in order to investigate the effect of infill thickness on the shear strength. Attempts are made to incorporate the results into Barton's formulation.

\subsection{Numerical simulation in PFC3D}

The bond-particle model adopted by the PFC3D code is described by Potyondy and Cundall (2004). The fundamental concept behind the model is to discretize rock masses into assemblies of interactive spherical bodies, all of which are rigid. The movement of these spherical bodies follows Newton's second law. The interaction between bodies is defined by bonds, which are formed when two bodies are in contact. Stiffness, strength and stress-strain relationship can be defined in both shearing and normal directions. The bond breaks when stresses exceed the associated strengths.
According to Potyondy and Cundall (2004), this model shows its validity in reproducing mechanical properties of rocks, such as fracturing, strength, dilation and strain-softening.

\subsection{Smooth-joint model}

PFC3D has also been used by number of researchers to simulate rock joint behaviour. The traditional way is to remove the bonds between the spherical bodies along the joint surface. The bond-removal method is adopted by Park and Song (2009). As claimed by Lambert and Coll (2014), this method will generate a joint surface with a JRC higher than expected, because the spherical shape of the elements will add extra asperity to the joint surface. An alternative method is to adopt the smooth-joint model (Pierce et al. 2007). A typical smooth-joint model is demonstrated in Fig. 1. Overlapping is allowed during shearing, unlike in the bondremoval method which forces the elements to override on each other (PFC3D 2005). In the three-dimensional smooth-joint model, forces are transferred homogeneously across a circular cross-section, and the area is defined by Eq. 9.

$A=\pi \bar{R}^{2}$

The radius of its cross-section $\bar{R}$ is defined by Eq. 10 .

$\bar{R}=\bar{\lambda} \min \left(R_{1}, R_{2}\right)$

where $\bar{\lambda}$ is the radius multiplier, $R_{1}$ and $R_{2}$ are the radii of the particles forming the smooth-joint contact. The
Fig. 1 Illustration of the smooth-joint model (PFC3D 2005)

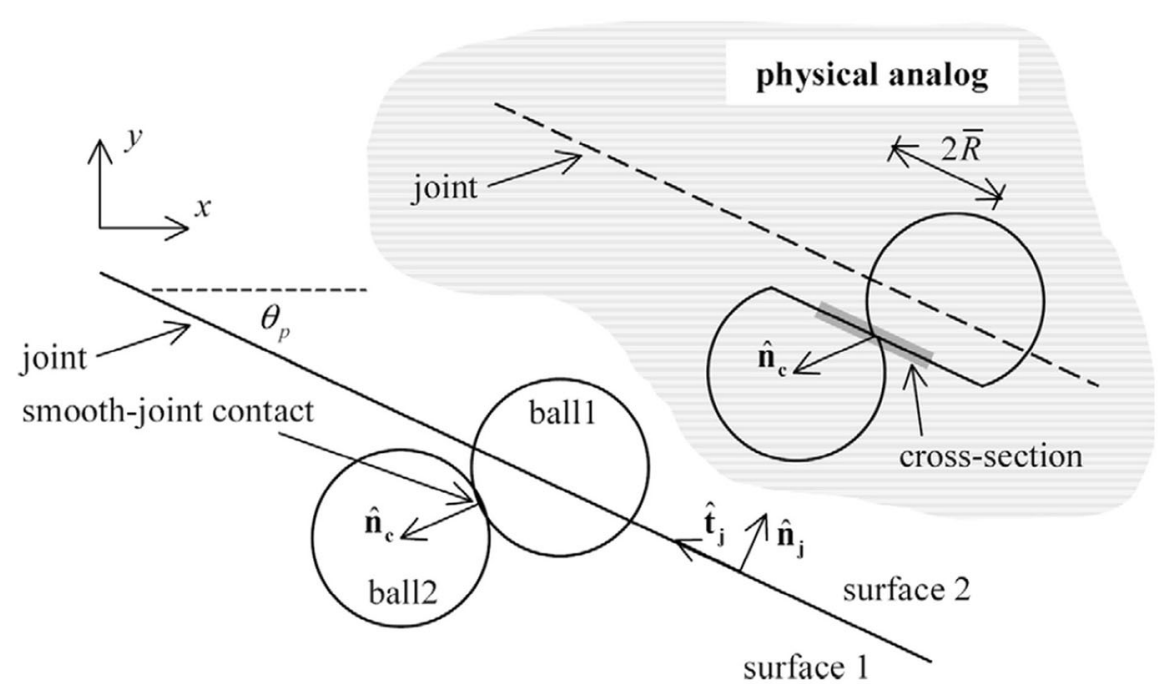


total force and displacement are defined by Eqs. 11 and 12 .

$$
\begin{aligned}
& \vec{F}=F_{n} \hat{n}_{j}+\vec{F}_{s} \\
& \vec{U}=U_{n} \hat{n}_{j}+\vec{U}_{s}
\end{aligned}
$$

where $F_{n}$ and $U_{n}$ are the magnitude of force and displacement in normal direction, $\vec{F}_{s}$ and $\vec{U}_{s}$ are the vectors of force and displacement in shear direction and $\hat{n}_{j}$ is the unit vector normal to the joint trajectory. The strength of the unbounded model is defined by the Coulomb model, which is often described by three parameters, including normal stiffness $\bar{k}_{n}$, shear stiffness $\bar{k}_{s}$ and friction angle $\mu$. The increment of elastic deformation is calculated within each simulation cycle in both normal and shear directions, which are denoted by $\Delta U_{n}^{e}$ and $\Delta \vec{U}_{s}^{e}$ respectively. The normal and shear forces are updated by Eqs. 13 and 14.

$F_{n}=F_{n}+\bar{k}_{n} A \Delta U_{n}^{e}$

$\vec{F}_{s}^{\prime}=\vec{F}_{s}-\bar{k}_{s} A \Delta \vec{U}_{s}^{e}$

Fig. 2 Constitutive relations for unbonded joint model (a) normal force versus normal displacement, (b) shear force versus shear displacement, (c) strength envelope and (d) normal displacement versus shear displacement during sliding (PFC3D 2005)
Since there is an upper limit of the shear stress, the final shear force is described by Eq. 15 .

$\left|\vec{F}_{s}\right|=\min \left(F_{s}^{*},\left|\vec{F}_{s}^{\prime}\right|\right)$

where $F_{s}^{*}$ is the peak shear stress and defined by Eq. 16.

$F_{s}^{*}=\mu F_{n}$

Force-displacement relationship is demonstrated in Fig. 2. In this paper, the smooth-joint model is used to simulate the interface between the wall rocks in a fresh joint and the interface between wall rock and infill materials in a filled joint, since the joint profile has to be maintained to obtain a constant JRC.

\subsection{Flat-joint model}

Traditionally, parallel-bond models are often used in simulating rock mass behaviour. The model suffers from the incapability of generating a realistic ratio of the uniaxial compressive strength to tensile strength for intact rock. This ratio given by parallel-bond model has a magnitude less than 10 , while for true (a)

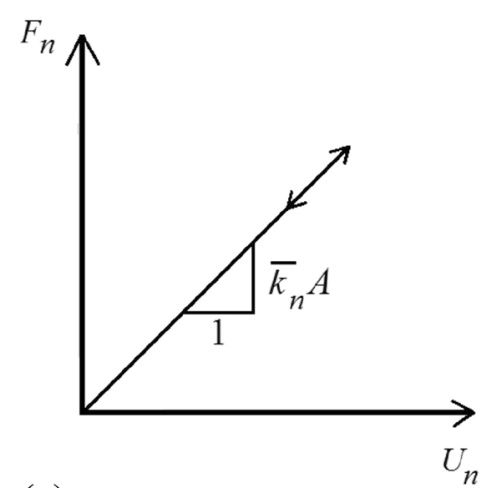

(c)

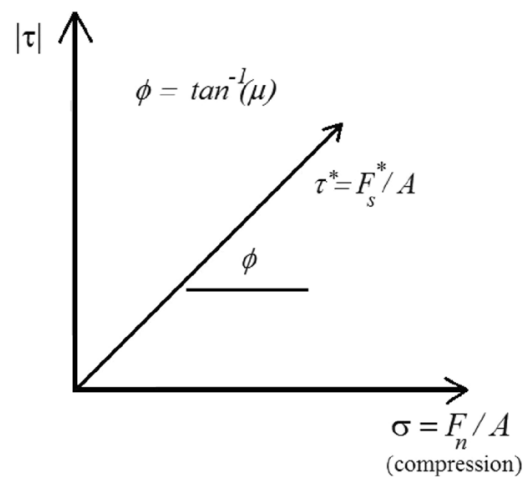

(b)

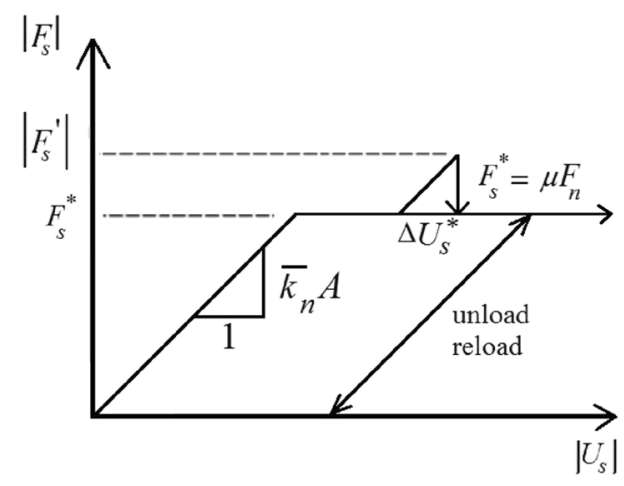

(d)

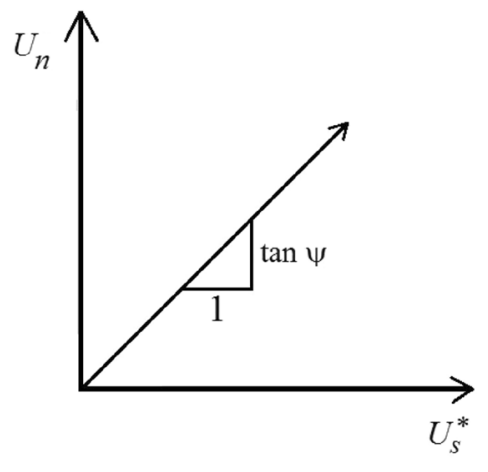


rock, it is around 20. The reason behind is the insufficient transference of angular momentum when a parallel bond has been broken. The flat-joint model is proposed by Potyondy (2012) and helps to resolve this problem. It is noted that the model is used to simulate intact rocks rather than joints despite of its name. In this specific model, a bond is decomposed to a predefined number of micro-bonds which are homogeneously distributed on the contact surface, and thereby preserves the ability to transfer angular momentum after bond breaking. Potyondy (2012) claims the advantage of using the flat-joint model by conducting calibration on two types of rocks.

In the current research, the wall rock of the joint is simulated by the flat-joint model, since tensile cracking is a mechanism involved in the shearing process, which is controlled by the tensile strength of wall rock. A list of microscopic parameters of the flat-joint model and the resulting macroscopic wall rock properties is demonstrated in Table 1.

\subsection{Joint profile}

A joint profile is experimentally studied and used in the simulation as the joint surface. The sample is collected from a rockslide in Jiweishan Mountain on June 5, 2009. The rock type of the sample is limestone. Shear tests, tile tests and Schmidt Hammer tests have been conducted to validate the method of using roughness coefficient $\lambda$ to estimate the JRC value. The joint profile is $62.9 \mathrm{~mm} \times 53.8 \mathrm{~mm}$ in dimension and the amplitudes are scanned at a $5 \mathrm{~mm} \times 5 \mathrm{~mm}$ resolution. The polygons incorporated into PFC3D model as to represent the joint profile is shown in Fig. 3a. Suggested value and both upper and lower limits of the JRC are then calculated. Since the method proposed by Zhang et al. (2014) is applicable to onedimensional joint profile, the JRC of each scanned line on the shearing direction is firstly obtained and the JRC of the entire two-dimensional profile is calculated by taking the average value. Suggested value of JRC is 8.96 with a lower limit of 7.00 and an upper limit of 12.15 .

\subsection{Shear test set-up}

To simulate shear tests, both normal and shear loadings have to be applied to the specimen. Different to those boundary element methods in which forces
Table 1 Wall rock and infill material properties

\begin{tabular}{lll}
\hline Parameters & Values \\
\cline { 2 - 3 } & Wall rock & Infill material \\
\hline Microscopic & & \\
Density $\left(\rho, \mathrm{kg} / \mathrm{m}^{3}\right)$ & 2730 & 1900 \\
Number of elements & 4 & - \\
Ball elasticity $\left(E_{c}, \mathrm{GPa}\right)$ & 35.0 & 10 \\
Tensile strength $(\mathrm{kPa})$ & 12,900 & 25.0 \\
Cohesive strength $(\mathrm{kPa})$ & 90,000 & 50.0 \\
Stiffness ratio $\left(k_{n} / k_{s}\right)$ & 1.25 & 2.5 \\
Friction coefficient & 0.5 & 0.3 \\
Radius multiplier & 1.0 & 1.0 \\
Macroscopic & & \\
UCS $(\mathrm{MPa})$ & 186.7 & - \\
Young modulus $(G, \mathrm{GPa})$ & 53.7 & - \\
Tensile strength $(\mathrm{MPa})$ & 9.08 & - \\
Friction angle $\left({ }^{\circ}\right)$ & - & 13.38 \\
Cohesion $(\mathrm{kPa})$ & - & 238 \\
\hline
\end{tabular}

can be directly specified, forces can only be applied through walls in PFC3D. There exist bonds between a wall and spherical bodies, and thereby forces can be transferred by moving the wall. The shear loading is applied by moving the two walls in contact with the upper half of the specimen along the shearing direction. The strain rate is kept as $0.03 \mathrm{~m} / \mathrm{s}$. As claimed by Bahaddini et al. (2013) a strain rate lower than $0.1 \mathrm{~m} / \mathrm{s}$ is slow enough for the specimen to maintain a quasistatic equilibrium in a two-dimensional case. In this three dimensional case, more time should be allowed, but low strain rate will result in a significantly long time for simulation. Therefore, the strain rate is chosen which allows time for the specimen to be quasi-static but still maintain an acceptable simulation time. The total normal contact force between the two walls and balls is recorded. All the walls are set as frictionless, by restricting the friction and shear modulus of those ball-facet bonds to null. It is for the purpose of shear strength calculation, as in this way shear force is solely composed of the contact forces on the two moving walls along the shear direction. Normal loading is applied by the moving of the top wall whilst fixing the bottom wall. The normal loading has to be fixed throughout the shear test, but the movement of balls will influence the contact force on the top the wall. Therefore, the servo-control mechanism has to be adopted to maintain the contact force. The immediate 


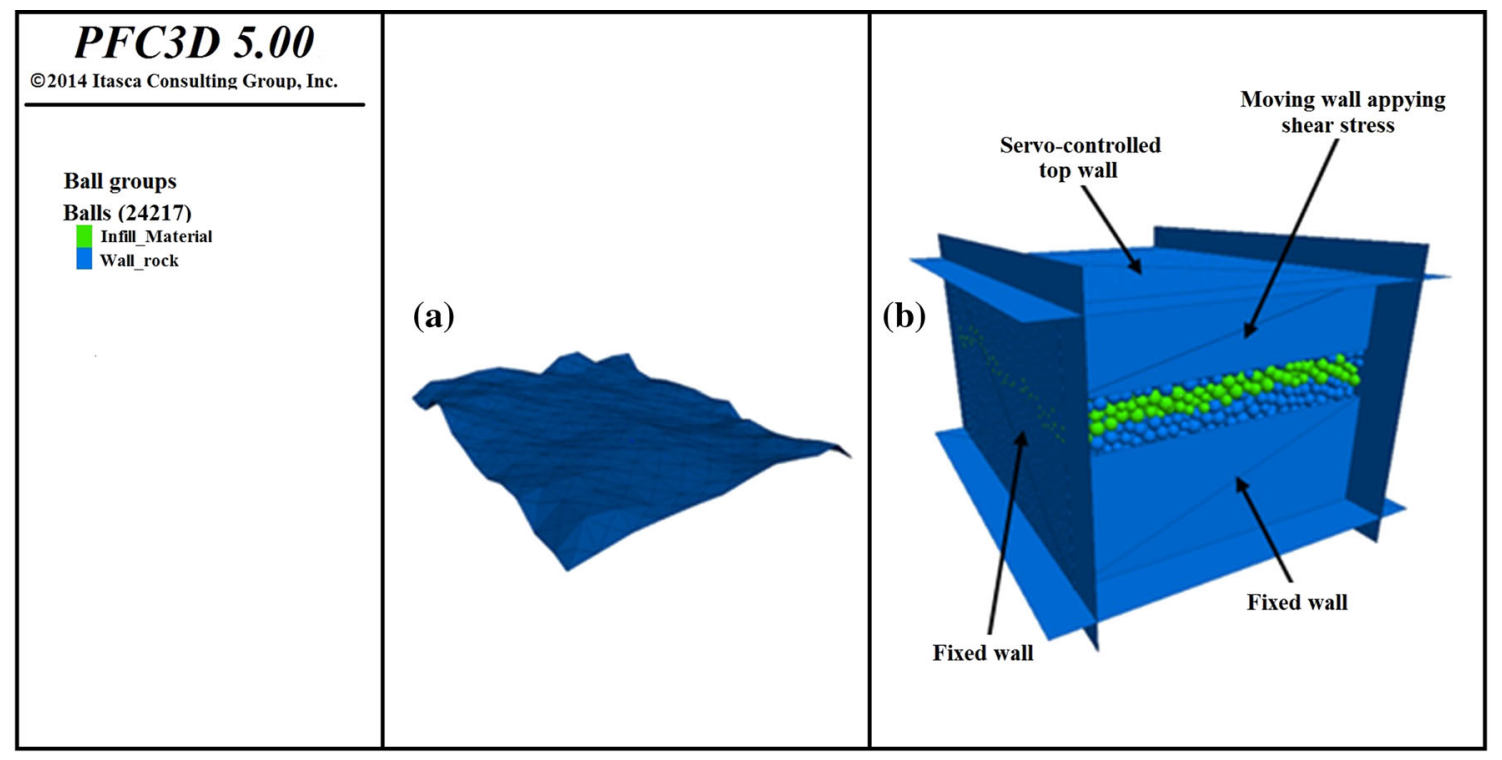

Fig. 3 a Joint profile represented by polygons in PFC3D b shear test set-up

contact force on the top wall is obtained in each simulation cycle and the velocity is reset based on the difference between the contact force and the required normal loading. An upward velocity is given to the top wall provided the contact force is higher than the required normal loading, and vice versa. The algorithm for calculating the velocity is given by PFC3D (2005), as Eq. 17.

$\dot{u}=G\left(\sigma_{w}-\sigma_{t}\right)=G \Delta \sigma$

where $\sigma_{w}$ is the immediate normal stress, $\sigma_{t}$ is the required normal stress and $G$ is the gain factor. The gain factor can be determined by Eq. 18 .

$G \leq \frac{\alpha A}{K_{n} \Delta t}$

where $A$ is the total contact area of the top wall, $K_{n}$ is the sum of normal stiffness of all contacts that are connected to the top wall, $\Delta t$ is the cycle time and $\alpha$ is an arbitrary coefficient. In this work, $\alpha$ is set to 0.7 so that the normal loading is kept as constant with minimum fluctuation.

The shear test set-up is illustrated in Fig. 3b. It is validated by conducting shear tests on the fresh joint profile described earlier. The normal stress is set ranging from 1 to $5 \mathrm{MPa}$. Simulation results are demonstrated in Fig. 3. The Barton's envelope is obtained by the following method. The JCS value is a known parameter which is set as equal to the UCS of the wall rock. The unknown parameters are the JRC and the residual friction angle. Excel Solver is used to obtain these two parameters which minimise the mean square error between simulating results and theoretical values given by Barton's model. The best-fitted Barton's envelope has a JRC of 8.27 and residual friction angle of $25.96^{\circ}$. The fitted JRC value is within the range and close to the suggested value, which validates the simulation set-up of the shear test. Comparison between the simulated value of shear strength and the predicted value given by Barton's model adopting the method proposed by Zhang et al. (2014) is shown in Fig. 4.

\subsection{Infill material}

Balls representing the infill material is then added inbetween the joint surface. One of the most common infill types is clay, which is a loose soil-like material. In PFC3D, the parallel-bond model can be used to simulate the infill material. Bond properties of the infill are also included in Table 1 . The bond strengths of the infill material are significantly lower than the wall rock. Ball size of the infill material is scaled small enough to ensure that at least two layers of balls are presented within the joint surface. Figure 5 shows the influence of infill thickness on the shear strength of joint under $90 \mathrm{kPa}$ normal stress level. As can be seen from the Figure, peak shear stress and residual stress 


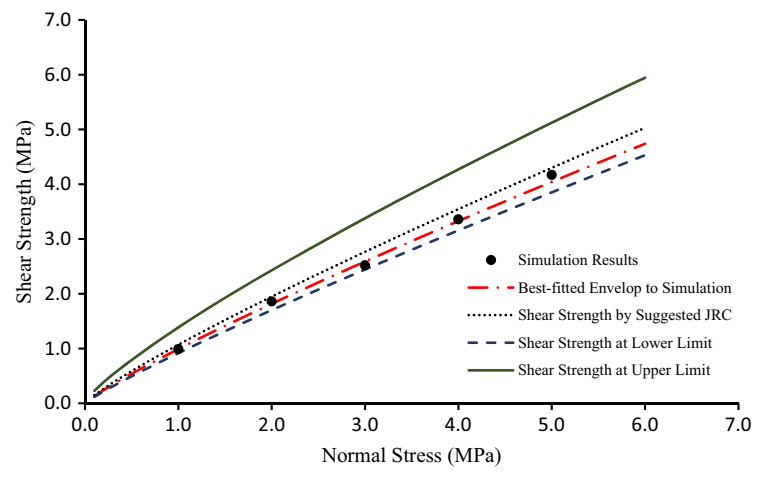

Fig. 4 Comparison between simulated results and Barton's model for the fresh joint

gradually decreases as the infill thickness increases. The infill thicknesses to be tested range from 1 to $6 \mathrm{~mm}$, which are at the same magnitude of the asperity amplitude of the joint profile. This range is chosen because there will be interaction between joint surface and infill material. If the thickness of the infill material is significantly higher than the asperity amplitude, the shear strength of the joint is solely ruled by the strength of infill material and thereby adopting Barton's model is meaningless. A filled joint model in PFC3D is shown in Fig. 6a. Those contact models used in different region of the specimen are demonstrated in Fig. 6 b.

\section{Results}

The simulation results of all the shear tests are plotted in Fig. 7. A Barton's envelope is generated at each

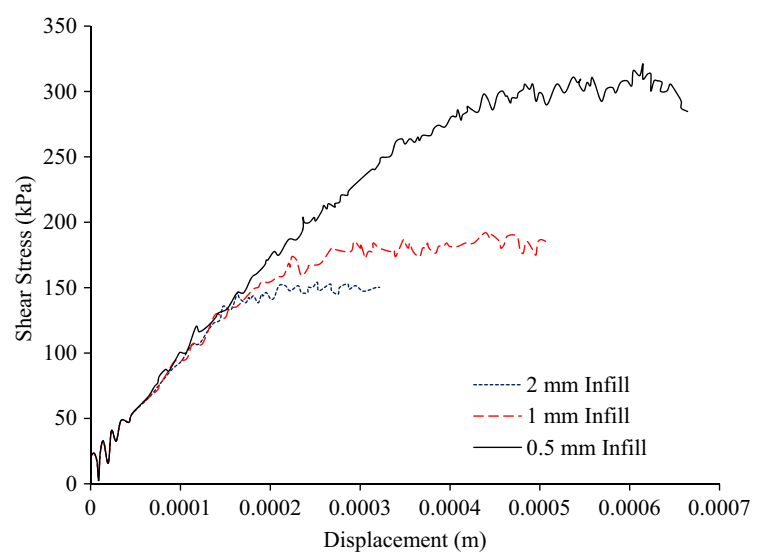

Fig. 5 Example of shear stress versus shear displacement at $90 \mathrm{kPa}$ normal stress for various infill thicknesses infill thickness. The JRC values for these envelopes are fixed as 8.29 which is the same to the JRC obtained from shear test on the fresh joint. The residual friction angle for the filled joints is scaled to equivalent to the friction angle of the infill material. Curve fitting is then conducted by using excel solver which minimise the mean square error to obtain the JCS values. The resulting values of the three parameters are shown in Table 2 at different infill thickness. Figure 8 shows the reduction of the JCS as an increase of the infill thickness. At low infill thickness the JCS decreases significantly, while above a threshold a much gentler decreasing trend can be observed. In Barton's model, JCS is not only a factor that scales the effect of normal stress but also a factor that affects the behaviour of JRC. In a joint with higher JCS, the multiplying factor $\log _{10}\left(\frac{J C S}{\sigma_{n}}\right)$ on JRC would be higher, which thereby increase the effect of JRC, and vice versa. Therefore, based on the current results, inclusion of infill material reduces the effect of the joint roughness on its peak shear strength and there exist a threshold phenomenon that above a certain infill thickness the effect of JRC is reduced to a consistently low level.

Alternatively, the inclusion of infill thickness can be interpreted as a reduction factor on the peak shear strength of the corresponding fresh joint. Figure 9 plots the peak shear strength against the infill thickness at each normal stress level. In general, the shear strength reduces with infill thickness. An inverse law is obtained to fit the results, formulated by Eq. 19.

$\tau\left(t, \sigma_{n}\right)=\frac{\tau_{\text {fresh }}\left(\sigma_{n}\right)-\tau_{\text {infill }}\left(\sigma_{n}\right)}{k\left(\sigma_{n}\right) t+1}+\tau_{\text {infill }}\left(\sigma_{n}\right)$

where $t$ is the infill thickness in millimetres, $\sigma_{n}$ is the normal stress, $\tau_{\text {fresh }}$ is the shear strength of a fresh joint, $\tau_{\text {infill }}$ is the shear strength of infill material and $k$ is the material-related reduction factor. $\tau_{\text {fresh }}$ can be obtained from Barton's model while $\tau_{\text {infill }}$ can be obtained from the shear box tests on the infill material. The reduction factor $k$ has a dependence on the normal stress applied which in this case is fitted by the Eq. 20 .

$k\left(\sigma_{n}\right)=6.16 \times 1.72^{-\sigma_{n}}+1.26$

The normal stress $\sigma_{n}$ in Eq. 20 is in MPa. The relation should be different based on the joint profile and infill properties. The shear strength reduces more quickly with infill thickness at lower normal stress. At high normal stress this reduction becomes gentle. The 


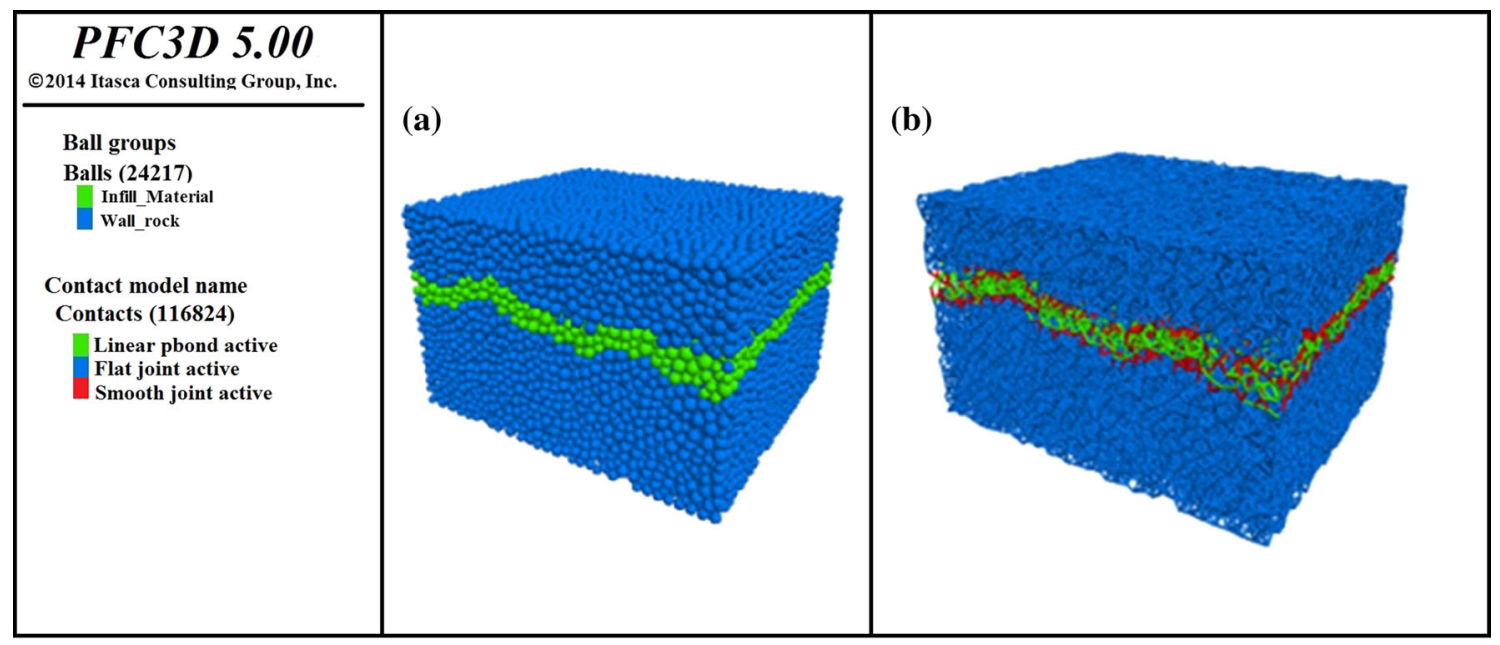

Fig. 6 PFC3D specimen shown in a ball groups $\mathbf{b}$ contact models

reason behind is that the effect of joint roughness on the shear strength depends on the normal stress. At lower normal stress, there exists less asperity interlocking and thereby the effect of infill material becomes more significant. At higher normal stress,

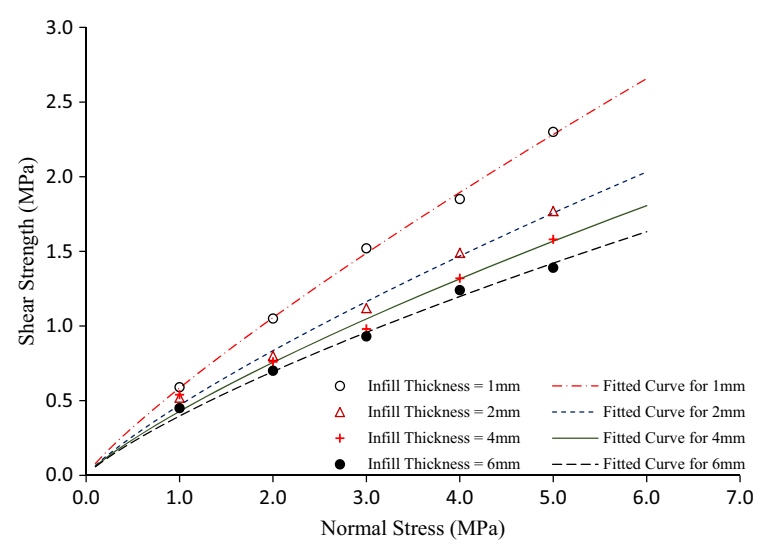

Fig. 7 Simulated results for different infill thickness asperities interact with the infill material more actively, which in turn increases the effect of the rough joint profile. As shown in Fig. 9, good agreement can be found between the simulated results and this model.

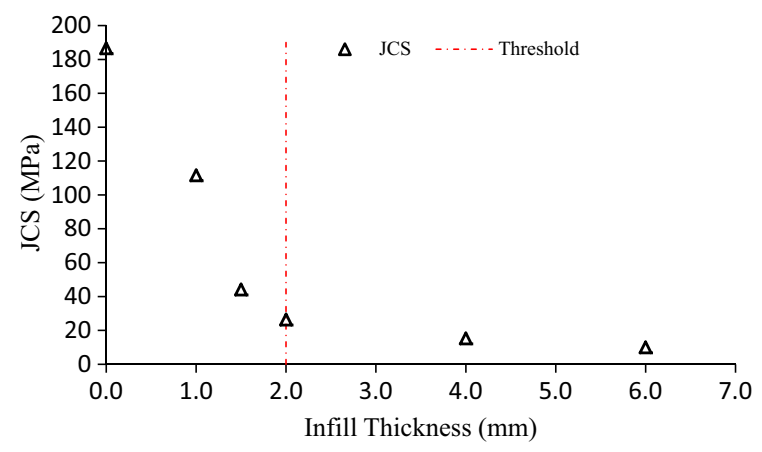

Fig. 8 Reduction of JCS according to infill thickness
Table 2 Fitted parameters of Barton's model for different infill thickness

\begin{tabular}{lccc}
\hline Infill thickness $(\mathrm{mm})$ & JRC & JCS $(\mathrm{MPa})$ & Residual friction angle $\left(^{\circ}\right)$ \\
\hline Fresh & 8.27 & 186.7 & 25.96 \\
1.0 & & 111.7 & 13.38 \\
1.5 & & 44.2 & \\
2.0 & 26.4 & \\
4.0 & 15.3 & \\
6.0 & 10.0 & \\
\hline
\end{tabular}




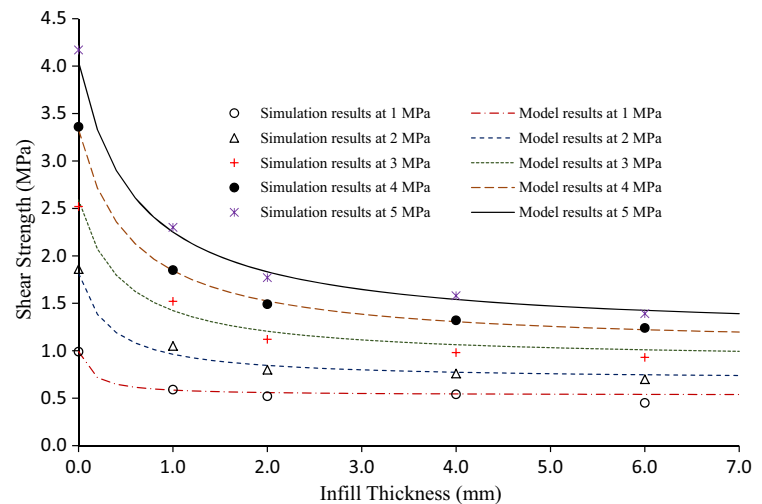

Fig. 9 Comparison between simulated results and modelled shear strength at various normal stresses

\section{Conclusions}

In this work, the effect of infill thickness on the shear strength of rock joint is investigated by PFC3D. The flat-joint model is selected for the wall rock, while smooth-joint model is used for the rock-infill interface and parallel-bond model for the infill material. The normal loading is manipulated by the servo-control mechanism. Normal stress tested on the joint profile ranges from 1 to $5 \mathrm{MPa}$. The simulation set-up is validated by comparing the resulting JRC with suggested JRC given by the method proposed by Zhang et al. (2014). The resulting JRC is 8.27 and matches with the suggested JRC which is 8.96. Infill material is added in-between the joint surface at thickness ranging from 1 to $6 \mathrm{~mm}$.

Attempts have been made to incorporate the results into Barton's formulation joint strength. A reduction of shear strength of filled joints can be observed as the infill thickness increases. The effect can be interpreted in two different ways. Inclusion of infill material behaves as a degradation factor of JCS and thereby minimises the effect of joint roughness. There exists a threshold phenomenon, as the JCS decreases significantly at low infill thickness, while above a certain level reduce to a consistently low level. Another way is to view the infill inclusion as a reduction factor on the overall shear strength of a fresh joint. The joint strength can be modelled by Barton's formulation provided it is fresh and reduces with the infill thickness. The reduction follows an inverse function. The reduction factor $k$ has a negative exponential relation with the normal stress.

\section{References}

Bahaddini M, Sharrock G, Hebblewhite B (2013) Numerical direct shear tests to model the shear behaviour of rock joints. Comput Geotech 51:101-115

Barton N, Choubey V (1977) The shear strength of rock joints in theory and practice. Rock Mech 10:1-54

Graselli G, Egger P (2003) Constitutive law for the shear strength of rock joints based on three-dimensional surface parameters. Int J Rock Mech Min Sci 40:25-40

Huang SL, Oelfke SM, Speck RC (1992) Applicability of fractal characterization and modelling to rock joint profiles. Int $\mathrm{J}$ Rock Mech Min Sci Geomech Abstr 29:89-98

Indraratna B, Haque A (1997) Experimental study of shear behavior of rock joints under constant normal stiffness conditions. Int J Rock Mech Min Sci 34(3-4): 141.e1-141.e14

Indraratna B, Premadasa W, Brown ET, Gens A, Heitor A (2014) Shear strength of rock joints influenced by compacted infill. Int J Rock Mech Min Sci 70:296-307

Lambert C, Coll C (2014) Discrete modeling of rock joints with a smooth-joint contact model. J Rock Mech Geotech Eng $6: 1-12$

Maerz NH, Franklin JA, Bennett CP (1990) Joint roughness measurement using shadow profilometry. Int J Rock Mech Min Sci Geomech Abstr 27:329-343

Mandelbrot BB (1967) How long is the coast of Britain. Science 156:636-638

Miller RP (1965) Engineering classification and index properties for intact rock. Ph.D. thesis, University of Illinois, Urbana-Champaign campus, p 333

Papaliangas T, Hencher S, Lumsden A, Manolopoulou S (1993) The effect of frictional fill thickness on the shear strength of rock discontinuities. Int J Rock Mech Min Sci Geomech Abstr 30(2):81-91

Park JW, Song JJ (2009) Numerical simulation of a direct shear test on a rock joint using a bonded-particle model. Int $\mathbf{J}$ Rock Mech Min Sci 46:1315-1328

Pereira JP (1997) Rolling friction and shear behaviour of rock discontinuities filled with sand. Int J Rock Mech Min Sci 34:244.e1-244.e17

PFC3D (2005) Itasca Consulting Group. Inc, Minneapolis

Pierce M, Cundall P, Potyondy D, Ivars DM (2007) A synthetic rock mass model for jointed rock. In: Eberhardt E et al (eds) Rock mechanics: meeting society's challenges and demands, proc. 1st Canada-US rock mechanics symposium (Vancouver, Canada, May 2007), vol 1. Taylor \& Francis Group, London, pp 341-349

Potyondy DO (2012) A flat-jointed bonded-particle material for hard rock. In: 46th US rock mechanics/geomechanics symposium, proceedings, ARMA, Chicago, June 2012. Paper no. 12-501. Alexandria: ARMA. 2012

Potyondy D, Cundall P (2004) A bonded-particle model for rock. Int J Rock Mech Min Sci 41:1329-1364

Reeves MJ (1985) Rock surface roughness and frictional strength. Int J Rock Mech Min Sci Geomech Abstr 22(6):429-442

Sinha U, Singh B (2000) Testing of rock joints filled with gouge using a triaxial apparatus. Int J Rock Mech Min Sci 37:963-981 
Tse R, Cruden DM (1979) Estimating joint roughness coefficients. Int $\mathrm{J}$ Rock Mech Min Sci Geomech Abstr 16:303-307

Wang T, Xu D, Elsworth D, Zhou W (2016) Distinct element modeling of strength variation in jointed rock masses under uniaxial compression. Geomech Geophys Geo-Energy Geo-Resour 2:11-24

Wasantha PLP, Ranjith PG, Zhang QB, Xu T (2015) Do joint geometrical properties influence the fracturing behaviour of jointed rock? an investigation through joint orientation. Geomech Geophys Geo-Energy Geo-Resour 1:3-14

Xie H, Wang JA, Kwasniewski MA (1999) Multifractal characterization of rock fracture surfaces. Int J Rock Mech Min Sci 36:19-27

Zhang G, Karakus M, Tang H, Ge Y, Zhang I (2014) A new method estimating the 2D Joint Roughness Coefficient for discontinuity surfaces in rock masses. Int J Rock Mech Min Sci 72:191-198 